\begin{abstract}
Iranica
Abstracta Iranica Revue bibliographique pour le domaine irano-aryen

Volume 34-35-36 | 2017

Comptes rendus des publications de 2011-2013
\end{abstract}

\title{
David Stronach. The silver rhyta from Erebuni revisited
}

\section{Sébastien Gondet}

\section{(2) OpenEdition}

Journals

\section{Édition électronique}

URL : http://journals.openedition.org/abstractairanica/42111

DOI : 10.4000/abstractairanica.42111

ISSN : 1961-960X

Éditeur :

CNRS (UMR 7528 Mondes iraniens et indiens), Éditions de l'IFRI

Référence électronique

Sébastien Gondet, "David Stronach. The silver rhyta from Erebuni revisited», Abstracta Iranica [En ligne], Volume 34-35-36 | 2017, document 110, mis en ligne le 30 juillet 2017, consulté le 26 septembre 2020 URL : http://journals.openedition.org/abstractairanica/42111; DOI : https://doi.org/10.4000/ abstractairanica.42111

Ce document a été généré automatiquement le 26 septembre 2020.

Tous droits réservés 


\section{David Stronach. The silver rhyta from Erebuni revisited}

Sébastien Gondet 


\section{RÉFÉRENCE}

David Stronach. «The silver rhyta from Erebuni revisited», in: P. Avetisyan, A.

Bobokhyan, eds., Archaeology of Armenia in regional context. Proceedings of the International Conference dedicated to the 50th Anniversary of the Institute of Archaeology and Ethnography. Held on September 15-17, 2009 in Yerevan. Yerevan, 2012, p. 170-184.

1 Alors qu'en 2009 D. Stronach vient de relancer des fouilles sur le site d'Erebuni (Arménie), cette communication est l'occasion pour lui de réexaminer les trois rhytons en argent retrouvés au cours de fouilles conduites au pied de la colline de la citadelle dont la fondation date de l'époque Urartu. L’A. s'appuie sur les différents articles déjà publiés sur ces objets pour redonner une description détaillée de ces trois rhytons. Ces rhytons à protomé ou tête d'animaux s'inspirent tous de canons perses mais s'en écartent sur plusieurs points. Leur analyse démontre qu'il s'agit pour le premier d'une production d'époque achéménide intégrant des éléments locaux arméniens, pour le second d'une production probablement post-achéménide, pour le troisième d'une importation anatolienne. L'A. situe leur fabrication entre le $\mathrm{V}^{\mathrm{e}} \mathrm{s}$. av. J.-C. et la fin du IV Le site d'Erebuni continue donc incontestablement à être actif au cours de la période achéménide et post-achéménide. Ils témoignent de la demande de l'élite locale en objets de luxe produits localement ou importés.

2 On regrettera toutefois l'absence de discussion sur le contexte archéologique de ces découvertes alors qu'il est très rare de retrouver ce type d'objet en fouille car la plupart des rhytons de ce type proviennent de pillages. La présence de cette vaisselle de luxe n'appelle en outre que très peu de commentaires de la part de l'A. concernant le statut et la fonction du site au cours de l'époque achéménide, alors que cette vaisselle témoigne probablement de la présence d'une élite dirigeante à Erebuni.

\section{AUTEURS}

\section{SÉBASTIEN GONDET}

UMR 5133 CNRS-Université de Lyon 